\title{
Assessing the mental state through a blog: psychiatry in the 21st century?
}

\author{
Philippe Wuyts, ${ }^{1,2}$ Matthew Broome, ${ }^{3}$ Philip McGuire ${ }^{1}$
}

The Psychiatrist (2011), 35, 361-363, doi: 10.1192/pb.bp.110.030825

${ }^{1}$ King's College London, Institute of Psychiatry, Department of Psychosis Studies, UK: ${ }^{2}$ Universitair Psychiatrisch Centrum, K.U. Leuven, Kortenberg, Belgium; ${ }^{3}$ Warwick Medical School, University of Warwick, Coventry, UK

Correspondence to Philippe Wuyts (philippe.wuyts@uc-kortenberg.be)

First received 15 Apr 2010, final revision 8 Mar 2011, accepted 21 Apr 2011
Summary Blogs have become increasingly popular over the past 15 years, especially with young people. In this editorial we discuss how the blogosphere is reshaping information exchange in healthcare. More specifically, blogs may change the doctorpatient relationship and provide clinically relevant information to mental health practitioners. However, the use of blogs as a source of clinical material raises ethical and legal issues.

Declaration of interest None.
The impact of blogs ('web logs') in medicine has been increasingly tangible over the past 10 years. ${ }^{1}$ Medical practitioners have joined in and are now using this tool to disseminate health information in many ways. A survey of medical bloggers demonstrated that they are highly educated and devoted writers, and that their blogs are frequently picked up by mainstream media, thus providing an important vehicle through which to inform the public as well as influence medical and health policy in general. ${ }^{2}$ Furthermore, it has been suggested that the vast amount of data found on health blogs could be collected and used for large-scale empirical investigations. ${ }^{3}$ An editorial in the journal Nature highlighted the scientific potential of the blog as a forum for interaction and discussion between researchers, ${ }^{4}$ whereas the website of the British Medical Journal has its own blog division (http://blogs.bmj.com), with blogs by medical professionals on many topics and encouraging readers and writers to discuss issues online.

Besides allowing dissemination of health information to the public or providing a new platform for discussion among professionals, the so-called 'social media' are increasingly used to directly communicate with patients ${ }^{5,6}$ and might reshape the relationship between mental healthcare professional and service user. In 2005, data from the American National Cancer Institute's Health Information National Trends Survey (HINTS) were said to portray 'a tectonic shift in the ways in which patients consume health and medical information'. ${ }^{7}$ However, even though the literature on social media and blogs in healthcare is substantially growing, the effects of keeping a personal blog on the mental health of the individual have yet to be investigated.

\section{Therapeutic value of personal blogs}

Blogs are a relatively recent phenomenon. They first appeared around 1994, but have become increasingly widespread on the internet, with millions of blogs registered with Technorati (www.technorati.com), the first blog search engine, alone. Blogs form a substantial part of the social media. They were first developed as personal online diaries, maintained by journalists and individuals on personal websites, but nowadays there are many different types of blogs. They vary in terms of the type of content (personal blogs, corporate blogs, etc.) and in the way the content is delivered (by primarily using text, video, etc.). In 1999, the term 'blogosphere' was coined, capturing the emergence of a new social network and a connected community online. ${ }^{8}$ In this editorial we will focus on the oldest form of blog, the personal blog. People keeping personal blogs may post anything there, from comments, music, videos and photos, to full online diaries containing personal and potentially sensitive information. Personal blogs are especially popular with adolescents and young adults. ${ }^{9}$

Maintaining a personal blog may have a positive effect on a person's mental health. Authors from the Department of Information Management, Chaoyang University of Technology, Taiwan, have posited that self-disclosure on a blog could significantly and directly affect a person's perception of social integration and their bonding social capital, which would in turn benefit their social well-being. ${ }^{10}$ Similarly to the Chinese authors, ${ }^{10}$ Schmitt et $a l^{11}$ concluded that by sharing thoughts about their moods and feelings with others through a blog, a young person may gain greater social support and improve their social integration as well as interpersonal communication, and thus improve their overall quality of life. The self-disclosure theory was supported by an American study in which middle-aged female bloggers whose blogs scored higher on selfdisclosure were more satisfied with online friendships than women whose blogs scored lower. ${ }^{12}$

A paper by Baker \& Moore $^{13}$ demonstrated that bloggers' social integration, reliable alliance and friendship satisfaction all significantly increased compared with those 
of non-bloggers, also supporting a notion that blogging has beneficial effects on well-being, specifically in terms of perceived social support. Furthermore, some authors have suggested that blogging might have a therapeutic value, not just owing to self-disclosure and improving social networking, but also by providing a means to reduce or cope with stress. ${ }^{14}$

\section{Blog as a source of information on the author's mental health}

When exploring the possible effects of blogging on individuals' mental well-being, the question that remains is what drives people to self-disclose on the internet. One hypothesis could be that individuals in distress, unable to form a sufficient social network, search on the internet for ways to cope.

As self-disclosure is essential to blogging, personal blogs often contain very personal and potentially sensitive information about the author, ranging from information on his or her past whereabouts and intimate friends, to detailed descriptions of the author's inner thoughts, feelings and experiences. Given that young people in distress especially are often reluctant to discuss their problems with others, their blogs might reveal the first signs of a psychiatric disorder developing. Emerging psychiatric disorders are often accompanied by atypical symptoms such as social withdrawal, lack of initiative, anxiety and paranoia. Rather than discussing them with peers or taking the necessary initiatives to arrange a face-to-face meeting with a mental health professional, a young person experiencing initial symptoms of an emerging mental health disorder may prefer to express his or her distress through a blog. The coinciding high popularity of blogging with people in their teens and early twenties and the high prevalence of developing mental disorders in those age groups warrant further investigation.

\section{Are blogs an unlimited but underexploited source of case information?}

Psychiatric assessment is still almost completely dependent on information obtained through history-taking and an assessment of the mental state. The information available from a psychiatric interview can be limited if the individual is unwilling or unable to provide it, or if the clinician is unable to detect it. Further gathering of information through observation, neuropsychological assessments or drawing from collateral history can only partly overcome this problem. Whereas patients' written diaries or journals usually remain hidden from mental healthcare practitioners, blogs might provide an easy and accessible way for patients to express themselves not only to the outside world but also to their caregivers. For example, in the case of depression, individuals will show lack of initiative, motivation and energy, all of which may act as obstacles to consulting mental healthcare professionals. In emerging psychosis, individuals might become increasingly paranoid and withdrawn. In this case, describing anomalous experiences and/or expressing increasing distress through a blog might not just alleviate stress but also alarm peers or mental health practitioners and facilitate quick access to mental healthcare. Besides the obvious usefulness in the assessment phase, blogs might also have an impact on communication between a mental healthcare practitioner and patient during the course of treatment.

However, even though accessing information from a patient's personal blog for clinical purposes might seem practical, it raises important ethical and potentially also legal issues.

\section{Self-disclosure $v$. privacy measures in the internet age}

Making personal and possibly sensitive information available on the internet could be harmful for the individual. In recent past, comments posted on a social network website and meant just for certain individuals have had far-stretching consequences for some of those involved, an issue widely covered in the media. Some people have lost their jobs when their contentious comments made on the social network site Facebook inadvertently reached the wrong person. ${ }^{15}$

In the 'internet era', where information can cross oceans in less than a second and sometimes ends up in the least anticipated places, privacy measures are becoming more and more stringent to protect sensitive information from becoming widespread. Similarly, people disclosing personal information through their blogs on the internet often do not realise the potential negative effects this might have.

Drawing from a legal framework, Article 19 of the Universal Declaration of Human Rights states that 'Everyone has the right to freedom of opinion and expression; this right includes freedom to hold opinions without interference and to seek, receive and impart information and ideas through any media and regardless of frontiers.' In addition, Article 8 of the European Convention on Human Rights states that 'Everyone has the right to respect for his private and family life, his home and his correspondence.' It might thus be concluded that everyone has the right to disseminate personal information into the public domain through a blog, even when it compromises his or her own privacy, when it is done with freedom of will and with own intent. Furthermore, it can be assumed that the UK Data Protection Act 1998 would not apply in such cases, as the information is disseminated by the individual themself.

In an attempt to express personal distress and look for stress relief, potentially precarious situations might emerge when sensitive and potentially damaging information is posted on the internet in the form of a personal blog, compromising the author's privacy and making potential misuse of this information by third parties possible. Individuals seeking stress relief through self-disclosing on the internet should be aware of this risk and take responsibility for their own actions.

\section{Should mental health professionals read their patients' blogs?}

What should be the role of mental healthcare professionals involved with people who keep a personal blog? It could be advocated that they should discuss the reasons as well as possible advantages and risks of posting personal 
information on the internet with their patients. In an ideal situation the need to self-disclose and/or express personal distress through a blog would decrease when a person feels 'contained' by mental healthcare professionals. However, more issues arise that need further consideration. If a clinician knows that a patient writes a blog, should they seek the patient's permission before reading it, even if the blog is in the public domain and thus accessible to everybody? If the patient declines to give permission to access the blog, are there circumstances when, for example in the interests of health and safety, this should be overridden? What if a patient's blog reveals intent to act in a dangerous or criminal way? To which extent could a mental health practitioner be held responsible to take action in such a case?

Maintaining a personal interaction and communication with patients remains essential to creating an environment of trust and confidentiality, where personal and sensitive issues can be discussed and where a space to self-disclose and seek stress relief is created. Information posted on blogs is in the public domain, accessible to anyone. Therefore, in the event of liability concerns, we feel that blogs cannot serve as a direct communication channel between service user and mental healthcare professional. In our view, mental healthcare professionals could not be held responsible to assess their patients' well-being through reading their personal blogs.

\section{Conclusions}

With the global rise of social media, new opportunities in healthcare communication have emerged both for healthcare professionals and the general public. Studies have demonstrated that keeping a personal blog can have a therapeutic effect, by reducing stress and improving subjective well-being, and could be considered especially useful for people experiencing mental health problems. However, the emergence of personal blogs not only creates new opportunities, but adds a new dimension to the service user-mental healthcare professional relationship. Many new challenges will emerge in the attempt to secure the benefits of social media while addressing the issues of privacy, responsibility and liability.

\section{About the authors}

Philippe Wuyts, Clinical Researcher, King's College London, Institute of Psychiatry, Department of Psychosis Studies, King's Health Partners,
London, UK, and Senior Psychiatry Registrar, Universitair Psychiatrisch Centrum, K.U. Leuven, Kortenberg, Belgium. Matthew Broome, Associate Clinical Professor of Psychiatry and Consultant Psychiatrist in Early Intervention, Division of Mental Health and Wellbeing, Warwick Medical School, University of Warwick, Coventry, and Honorary Senior Lecturer, Institute of Psychiatry, King's College London, UK. Philip McGuire, Professor of Psychiatry and Cognitive Neuroscience, King's College London, Institute of Psychiatry, Department of Psychosis Studies, King's Health Partners, London, UK

\section{References}

1 Schneider A, Jackson R, Baum N. Social media networking: blogging. J Med Pract Manage 2010; 26: 82-5.

2 Kovic I, Lulic I, Brumini G. Examining the medical blogosphere: an online survey of medical bloggers. J Med Internet Res 2008; 10: e28.

3 Miller EA, Pole A. Diagnosis blog: checking up on health blogs in the blogosphere. Am J Public Health 2010; 100: 1514-9.

4 Editorial. It's good to blog. Nature 2009; 457: 1058.

5 Verkamp J. Social media as a way to connect with patients. MGMA Connex 2010; 10: 46-9.

6 Wald HS, Dube CE, Anthony DC. Untangling the Web - the impact of Internet use on healthcare and the physician-patient relationship. Patient Educ Couns 2007; 68: 218-24.

7 Hesse BW, Nelson DE, Kreps GL, Croyle RT, Arora NK, Rimer BK, et al. Trust and sources of health information: the impact of the Internet and its implications for healthcare providers: findings from the first Health Information National Trends Survey. Arch Intern Med 2005; 165: 261824.

8 BradLands. It's Peter's fault. 10 September 1999 (http://www. bradlands.com/weblog/comments/september_10_1999/).

9 Williams AL, Merten MJ. A review of online social networking profiles by adolescents: implications for future research and intervention. J Adolescence 2008; 43: 253-74.

10 Ko HC, Kuo FY. Can blogging enhance subjective well-being through self-disclosure? Cyberpsychol Behav 2009; 12: 75-9.

11 Schmitt KL Davanim S, Matthias S. Personal homepage construction as an expression of social development. Dev Psychol 2008; 44: 496-506.

12 Bane CM, Cornish M, Erspamer N, Kampman L. Self-disclosure through weblogs and perceptions of online and 'real-life' friendships among female bloggers. Cyberpsychol Behav Soc Netw 2010; 13: 131-9.

13 Baker JR, Moore SM. Blogging as a social tool: a psychosocial examination of the effects of blogging. Cyberpsychol Behav 2008; 11: 747-9.

14 Wapner J. Blogging - it's good for you. The therapeutic value of blogging becomes a focus of study. Scientific American 2008; 22 May (http:// www.scientificamerican.com/article.cfm?id=the-healthy-type).

15 Chung J. Manhattan beep's aide resigns over Facebook comments on Gates arrest. Gothamist 2009; 28 July (http://gothamist.com/2009/ 07/28/manhattan_beeps_aide_resigns_over_f.php). 